\title{
Surface properties of low-density polyethylene treated by plasma immersion ion implantation for food packaging
}

\section{Propriedades de superfície do polietileno de baixa densidade tratado por implantação iônica por imersão em plasma para embalagens alimentícias}

Péricles Lopes Sant'Ana ${ }^{1 *}$, José Roberto Ribeiro Bortoleto1, Nilson Cristino da Cruz¹, Elidiane Cipriano Rangel,

Steven Frederick Durrant ${ }^{1}$, Laura Moreira Costa Botti ${ }^{2}$, Carlos Alberto Rodrigues dos Anjos ${ }^{2}$

\begin{abstract}
In this work, some surface properties of low-density polyethylene (LDPE) treated by plasma immersion ion implantation (PIII) are presented. The effects of PIII of the LDPE samples regarding surface structures, wettability and transparency in visible light were studied. The PIII was applied in a vacuum system at a total pressure of $13.33 \mathrm{~Pa}$. An applied power of $25 \mathrm{~W}$ at $13.56 \mathrm{MHz}$ was used for a fixed treatment time of $300 \mathrm{~s}$. Attenuated total reflection Fourier transform infrared spectroscopy (ATR-FTIR) detected the presence of new molecular groups on the treated LDPE surface. Reduced optical transmittance was observed in the visible region of the treated material. Contact angle measurements were useful to identify the hydrophilization of LDPE treated in nitrogen plasmas. The Stop and Range of lons in Matter (SRIM) simulation was used to model the distribution of implanted ions on LDPE matrix.
\end{abstract}

Keywords: LDPE, Surface treatment, PIII, FTIR, Optical transparency, SRIM.

\section{RESUMO}

Neste trabalho, são apresentadas algumas propriedades superficiais do polietileno de baixa densidade (PEBD) tratado por implantação iônica por imersão em plasma (PIII). Foram estudados os efeitos da IIIP das amostras de PEBD sobre as propriedades estruturais na superfície, molhabilidade e transparência na luz visível. A IIIP foi aplicada em um sistema de vácuo a uma pressão total de 13,33 Pa. Uma potência aplicada de $25 \mathrm{~W}$ a 13,56 MHz foi usada para tratamentos com tempo fixo de $300 \mathrm{~s}$. A espectroscopia por Reflexão total atenuada no infravermelho por transformada de Fourier (ATR-FTIR) detectou a presença de novos grupos moleculares na superfície do PEBD tratado. Uma redução na transmitância óptica foi observada na região da luz visível para o material tratado. As medidas de ângulo de contato foram úteis para identificar a hidrofilização do PEBD tratado em plasmas de nitrogênio. A parada e o alcance dos íons na matéria via simulação, (SRIM), foi usada para modelar a distribuição dos íons implantados na matriz polimérica do PEBD.

Palavras-chave: PEBD, tratamento superficial, IIIP, FTIR, transparência óptica, SRIM.

1. Universidade Estadual de São Paulo - Instituto de Ciência e Tecnologia de Sorocaba - Sorocaba (SP), Brazil

2.Universidade Estadual de Campinas - Campinas (SP), Brazil

*Correspondence author: drsantanap|@gmail.com

Received: 29 Jan 2019 Approved: 2 Mar 2020 


\section{INTRODUCTION}

Low-pressure plasma treatment is a promising technique which can improve the surface properties of the polymers without altering their bulk properties. Such technique forms an environmentally friendly alternative to conventional surface modification methods ${ }^{1}$. Plasma treatment is a relatively cheap and simple process for the fluorination of polymer surfaces ${ }^{2}$.

Radiofrequency (RF) plasmas using fluorinated gases can fluorinate surfaces at room temperature, thus avoiding thermal degradation of the material ${ }^{3}$. Nitrogen plasma surface treatment at low pressure improves adhesion properties of paints or other coatings ${ }^{4}$. More intense changes are obtained when the sample exposed to the plasma is polarized with pulses of high-negative voltage, thus attracting positive ions. The interaction of positive energetic ions with the atoms of the solid can cause excitation, ionization, fragmentation of chemical bonds, emission of molecular species and atomic displacements, inducing compositional changes and structural rearrangements. This process is known as plasma immersion ion implantation (PIII) and was created to overcome certain limitations of conventional implantation using ion beams ${ }^{5}$.

There are many techniques that can be used to modify the surface properties of materials by the addition of particles, coatings and functional groups ${ }^{6}$. The growing interest in ion-implanted polymeric materials, however, is due to their increasing demand in various disciplines. In this sense, the introduction of new technologies could lead to a reduction in processing time or an improvement in operating conditions, thereby decreasing both environmental and financial costs ${ }^{7}$.

Plasma treatments cause chemical and physical changes on the plasma-polymer interface, which improve surface properties ${ }^{8,9}$. Other results, including hydrophilization or fluorination of surfaces of commercial polymers using plasma immersion techniques, were discussed in the first author's doctoral thesis ${ }^{10}$ and can be found in recent papers ${ }^{11,12}$ regarding oxygen activation on the surface of LDPE as revealed by FTIR. Moreover, improvements were obtained in wettability character, determined by contact angle measurements, and in transmittance in the visible range, as revealed by ultraviolet-visible spectroscopy (UV-Vis). Works in the literature demonstrate the effectiveness of PIII to produce such changes in the surface properties of polymeric materials ${ }^{13}$.

\section{MATERIAL AND METHODS}

\section{LDPE substrates: preliminary considerations}

Low-density polyethylene (LDPE) or just polyethylene (PE) $\left(\mathrm{C}_{2} \mathrm{H}_{4}\right)_{\mathrm{n}}$ is an inexpensive and abundant thermoplastic that has excellent chemical and electrical resistance, low coefficient of friction, high resistance to moisture, and easy processing. The working range for processing this resin ranges from 40 to $93{ }^{\circ} \mathrm{C}$. Owing to the presence of amorphous (disordered) and crystalline (ordinate) regions ${ }^{14}$ Polyethylene is a semicrystalline polymer

The PEs are classified by density into families. Here, $\mathrm{d}$ is density in $\mathrm{g} \cdot \mathrm{cm}^{-3}$ :

i. Linear low-density polyethylene (LDPE) $(0.900<\mathrm{d}<0.915)$;

ii. Low-density polyethylene (LDPE) $(0.910<\mathrm{d}<0.925)$;

iii. Linear medium-density polyethylene (PELMD) $(0.926<\mathrm{d}<0.940)$;

iv. High-density polyethylene (HDPE) $(0.941<\mathrm{d}<0.959)$.

Each of these types presents its specific characteristics such as morphology, flexibility, transparency, and impact resistance ${ }^{15}$. Owing to their non-polar nature, Polyethylene's have high stability to chemical agents, being resistant to aqueous solutions of salts, inorganic acids and alkalis, up to $60^{\circ} \mathrm{C}$, PEs are stable in many solvents. Polyethylene films are used for various types of packaging because of their low cost and flexibility ${ }^{16}$.

Table 1 shows respectively:

i. Typical energy values of some plasma species, and;

ii. The energy required to break the chemical bond of some carbon-bound molecular species, which is the most common element in the polymer matrix of LDPE.

The interaction of plasma species with the surface can induce the formation of active sites (free radicals and excited species, for example), which can undergo a molecular rearrangement or chemically react with species from the atmosphere that surrounds this surface ${ }^{19}$. 
Table 1: Energy values of some species present in plasma and energy binding values of possible molecular species ${ }^{17,18}$.

\begin{tabular}{|c|c|}
\hline Plasma species & Associated energy (eV) \\
\hline Electrons & $0-20$ \\
\hline lons & $0-2$ \\
\hline Photons UV/visible & $3-40$ \\
\hline Molecular species & Bonding energy (eV) \\
C-H & 4.3 \\
C-N & 2.9 \\
C=O & 8.0 \\
C-C & 3.7 \\
C=C & 6.4 \\
Co $-\mathrm{C}$ & 8.4 \\
\hline
\end{tabular}

\section{Techniques selected for the experiment}

The experimental setup used consists of a stainless-steel vacuum chamber with two internal electrodes ${ }^{20}$, evacuated by a rotary pump $\left(18 \mathrm{~m}^{3} / \mathrm{h}\right)$ to $\sim 10^{-1} \mathrm{~Pa}$. Needle valves were employed to control the gas flows and a Barocel pressure sensor to monitor the chamber pressure. In this case, the total pressure of the reactor was constant at $100 \mathrm{mTorr}(13.33 \mathrm{~Pa})$. The treatment temperature and time were maintained constant at $298 \mathrm{~K}$ and $300 \mathrm{~s}$, respectively. The LDPE samples were placed on the lower electrode and directly exposed to the nitrogen plasma environment established by radiofrequency power $(13.56 \mathrm{MHz})$ at $25 \mathrm{~W}$ applied to the upper electrode while the lower electrode was supplied with negative pulses of $-1040 \mathrm{~V}$ at $300 \mathrm{~Hz}$. The cycle times used were 1, 30, 100 and $500 \mu$ s. The pulsed voltage was monitored by a digital oscilloscope (Tektronix TDS 2014). Figure 1 shows a scheme of the treatment system.

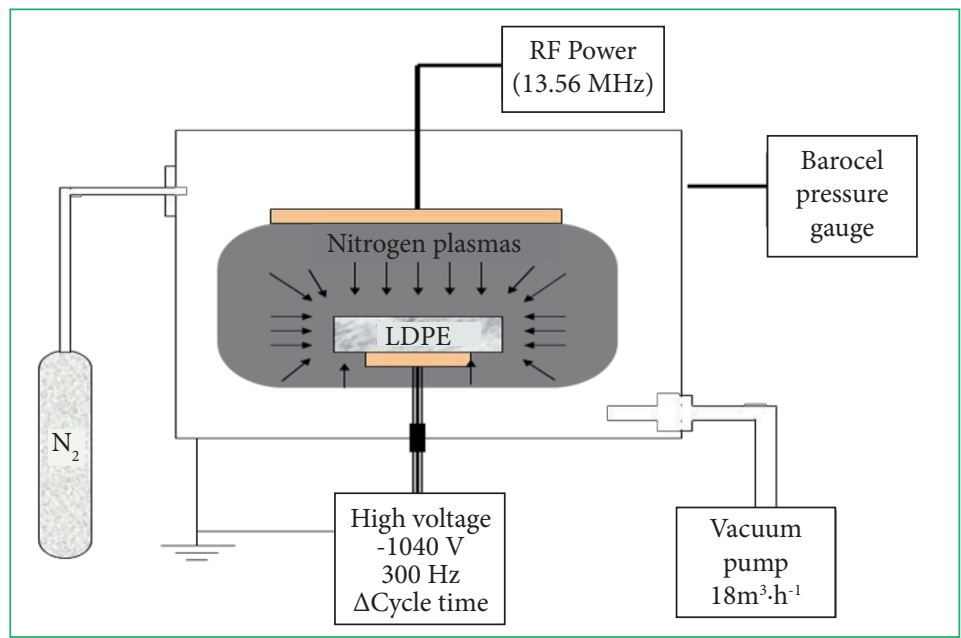

Figure 1: Scheme of the plasma immersion ion implantation system.

The effect of the plasma treatment on the chemical structure of the white LDPE surface was evaluated using a Jasco 410 FTIR infrared spectrometer ${ }^{21}$. Transmission spectra were collected for the virgin and plasma-treated samples. Contact angle measurements were obtained immediately after treatment using a Ramé-Hart 100-00 Goniometer, employing the sessile water drop technique ${ }^{22}$.

The Stop and Range of Ions in Matter (SRIM) software (2018) was run to reveal the maximum reach of 1 keV nitrogen ions in the LDPE (marlex) target (of density $\rho=0.93 \mathrm{~g} / \mathrm{cm}^{3}$ ). The function ion distribution with recoils and quick calculation of damage was used to provide a statistical estimate based on the Kinchin-Pease formalism ${ }^{23}$, in which the number of point defects generated by an implanted ion is derived analytically from the energy that is transferred from an ion to an atom of the target material ${ }^{24}$. It was anticipated that some organic compounds would appear after the treatment, which are responsible for the mechanism of hydrophilization of the surface ${ }^{25}$.

\section{RESULTS AND DISCUSSION}

\section{FTIR spectroscopy}

Treatment by PIII changes the chemical structure of the LDPE surface. Fig. 2 shows the FTIR spectra of the untreated and treated samples. Absorption bands and their attributions are indicated. 


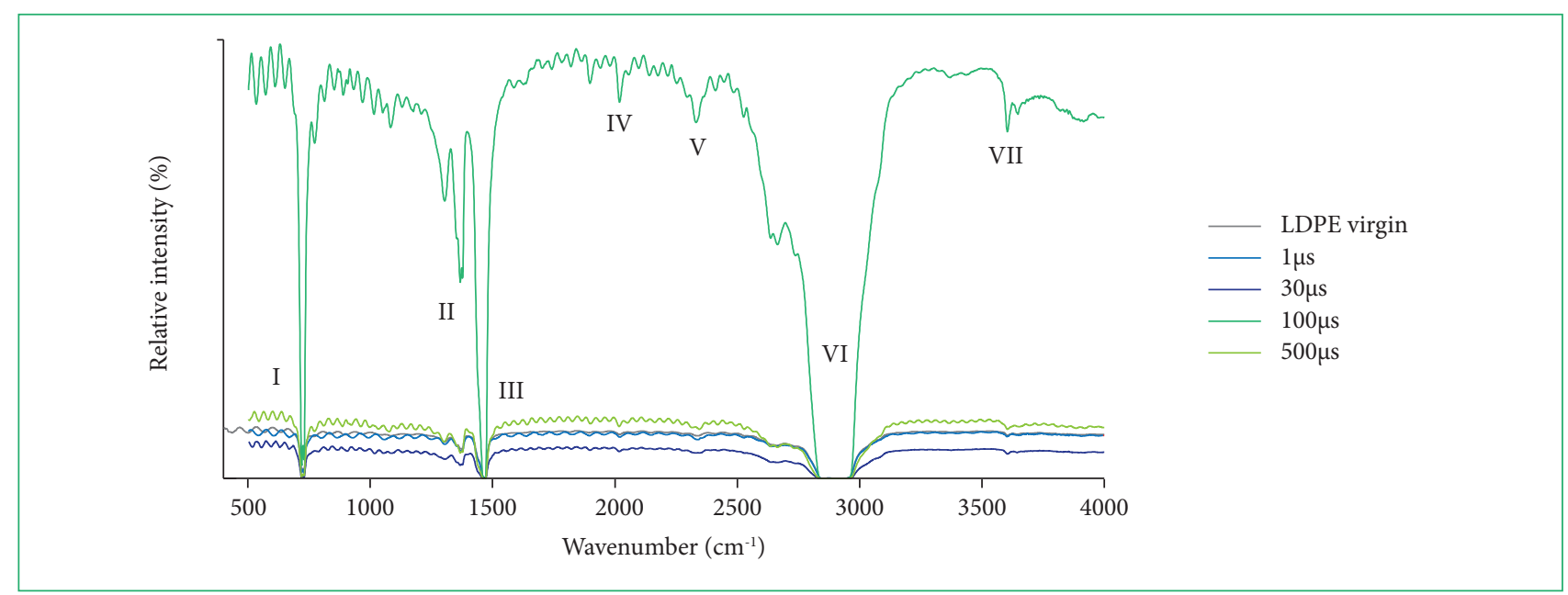

Figure 2: Infrared spectra of LDPE treated by PIII at $13.33 \mathrm{~Pa}, 25 \mathrm{~W}$ of RF power using $\mathrm{N}_{2}$ plasmas for $300 \mathrm{~s}$ for ion implantation cycle times (in $\mu \mathrm{s}$ ) of 1, 30, 100 and 500 .

Although it is primarily a qualitative analytical tool, it has been used to quantitatively gauge the concentrations of functional groups in plasma polymers and, hence, the crosslinking density of hydrocarbon plasma polymers ${ }^{26}$. An absorption in $3600 \cdot \mathrm{cm}^{-1}$ (VII) shows the presence of $-\mathrm{OH}$ on the treated surface. The presence of oxygen is explained by the free path even during the treatment or after the treatment. The residual oxygen makes chemical bonds with free path during plasma process, and also, free path captures oxygen from the air when the samples are exposed to the atmosphere after treatment ${ }^{27}$. Bonds of hydrogen are easily broken due to its weak bonds ${ }^{28}$. In fact, high voltage influences on the surface bonding configuration ${ }^{29}$.

The position and the bands as indicated on the FTIR spectra are similar for all LDPE samples, but their intensities are slightly different, such as a strong band in $2900 \cdot \mathrm{cm}^{-1}$ (VI) caused by C-H stretching vibrations in $\mathrm{CH}_{2}$. The variation is more evident at $500 \mu$ s, in which the intensity of the peaks at $2340 \cdot \mathrm{cm}^{-1}(\mathrm{~V}) \mathrm{N}-\mathrm{H}^{+}$, attributed to amine absorption, and correlated compounds at $\sim 1950 \cdot \mathrm{cm}^{-1}$, (IV) attributed to allenes $-\mathrm{C}=\mathrm{C}=\mathrm{C}-$, become stronger. The band at $1490 \cdot \mathrm{cm}^{-1}$ (III) is attributed to the $\mathrm{C}-\mathrm{H}$ bending vibrations of paraffin hydrocarbon ${ }^{30}$. The peaks at $1350 \cdot \mathrm{cm}^{-1}$ (II) are attributed to an axial deformation of the $\mathrm{C}-\mathrm{O}$ from carboxylic acid coupled to -OH. An absorption peaked around $730 \cdot \mathrm{cm}^{-1}(\mathrm{I})$ is attributed to angular asymmetrical in-plane deformation of $-\left(\mathrm{CH}_{2}\right)_{\mathrm{n}}-$.

\section{Contact angle measurements}

The contact angle of the liquid on a solid surface, which is closely related to the surface free energy, can be evaluated using the sessile drop technique with deionized water drops at room temperature ${ }^{31}$. Table 2 shows the contact angle as a function of the cycle time, showing that nitrogen plasmas are suitable for surface hydrophilization.

Table 2: Contact angle as function of cycle time of LDPE samples treated in $\mathrm{N}_{2}$ at $13.33 \mathrm{~Pa}, 25 \mathrm{~W}$ for $300 \mathrm{~s}$, for different ion implantation cycle times. The other parameters were $-1040 \mathrm{~V}$ and $300 \mathrm{~Hz}$.

\begin{tabular}{|c|c|}
\hline LDPE contact angle $\left(^{\circ}\right)$ & Cycle time $(\mu s)$ \\
\hline $76 \pm 1$ & 0 (untreated) \\
$30 \pm 1$ & 1 \\
$24 \pm 1$ & 30 \\
$17 \pm 2$ & 100 \\
$9 \pm 1$ & 500 \\
\hline
\end{tabular}

Increasing the cycle time decreases the water contact angle from $76^{\circ}$ for the untreated sample to $9^{\circ}$ for the samples treated at $500 \mu \mathrm{s}$. The results in this work are consistent with those of preview studies, showing that ion bombardment is effective in changing the surface contact angle ${ }^{32,33}$. The same hydrophilic behavior of polymeric samples was observed using nitrogen plasma treatment for textile industry applications $s^{34}$.

Possibly, polar groups formed by the recombination of free radicals contributed to the decrease in the contact angle of the LDPE samples. This is consistent with the FTIR spectra, because of the polar hydrocarbon and oxygen-containing groups formed on the surface, leading to hydrogen bonding with pure water. Polymer chains have a high degree of flexibility and mobility that allows the reordering of polar and nonpolar groups inside the material through translational and vibrational motion which cause the transient hydrophilic character ${ }^{35}$. 
Moreover, stability is an important and notable feature for some applications. For applications aimed at packaging-food interaction, it is possible to improve the chemical bonding of the polymer chain with other substances, like sugars (which have, in turn, polar groups) under certain treatment conditions, especially using nitrogen. As reported by Lee et al. ${ }^{36}$, the surface of the treated plastic also becomes suitable for other applications, such as industrial paints, protective layers, and self-cleaning/optical windows.

Although the treatment results in the incorporation of polar groups, polymer wettability does not involve only oxidative reactions. Loss and incorporation of new species, besides $\mathrm{O}$, may occur with ageing ${ }^{37}$. Along with chemical modifications, structural reorganization favors the reduction of the surface free energy. Thus, the stability of the treated surface is determined by the extent to which polar species can move, which depends upon the degree ofrosslinking ${ }^{38}$. The rise in the number of covalent bonds among neighboring chains, known as anchor points, limits vibrational and rotational movements.

\section{Plasma effect on the polymeric chain/SRIM simulation}

The exposure of $\mathrm{PE}$ to plasmas of any of the gases $\mathrm{He}, \mathrm{Ar}, \mathrm{Kr}, \mathrm{Ne}, \mathrm{Xe}, \mathrm{H}_{2}$ or $\mathrm{N}_{2}$, results in crosslinking of the surface. Hudis et al. ${ }^{39}$, working with a hydrogen plasma, demonstrated that such crosslinking could be explained on the basis of the interaction of the polyethylene with ultraviolet radiation from the plasma. According to Fig. 3, it is possible to notice the changes in the structure of the polymer chains.

(a)

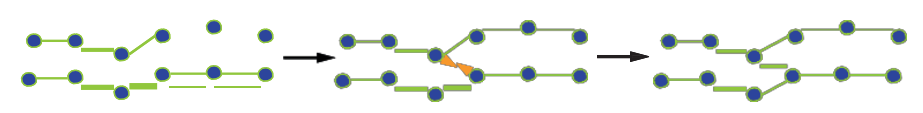

(b)

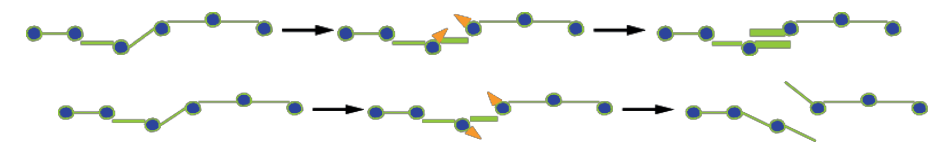

Figure 3: Plasma effect on polymeric chains caused by ionic bombardment: Electrons collision from the plasma ions to the backbone causes (a) cross-linked formation, (b) unsaturation. On the other hand, nuclear collisions can dissociate polymeric chains

(c) inducing volatile species that can be removed by the vacuum pump.

An excellent review of this early work on plasma interactions with polymers can be found in the literature ${ }^{40}$. In one of these studies ${ }^{41}$, some polymers including polyethylene, were treated with argon and nitrogen plasmas. It was found that nitrogen plasma treatment led to the incorporation of both oxygen and nitrogen functionalities.

Plasma immersion which in turn can be explained by the presence of hydrogen and oxygen incorporated onto its surface, as previously reported, increases the number of species with the same chemical affinity, leading to the formation of hydrogen bonds. To become stable after the treatment, the surface tends to reorient the short chain molecules and the oxygen-containing groups diffuse into the interior of the material ${ }^{42}$.

By observing the mechanism of oxygen incorporation, it is possible to explain the increase in wettability of samples treated with nitrogen. Small variations can be attributed to the structural reorganization occurred on the surface of the polymer after treatment. Polymer chains have a high degree of flexibility and mobility that allows the reordering of polar and nonpolar groups inside the material through translational and vibrational motion. Thus, the hydrophilic character may also vary depending upon ageing ${ }^{43}$.

It is noted that changes in the contact angle with ageing are usually much smaller for polymers that are highly crosslinked, since then the mobility of the polymeric chains ${ }^{44}$, and therefore, the reorganization of polar groups on the surface is attenuated. Carbon atoms can also be ejected and oxygen incorporation can be observed. The presence of oxygen in the reactor, either coming from residual gas or released from the glass chamber near the electrode region, may also account for this process. Therefore, the wetting of the bombardment surface is attributed to the electrostatic attraction between dipoles formed by O-containing groups in the LDPE surface and water molecules in the droplet ${ }^{45}$.

To analyze the structural changed caused by bombardment of ions from the plasma sheath region, a simulation was made using the Stop Range Ions in Matter (SRIM) Calculation 2008. The program was run to associate the changes in surface properties of implanted polymers with the ion-energy loss mechanisms (-dE/dx). The property improvements (mainly attributable to crosslinking) were related to electronic energy transfer (excitation and ionization), and the degradation in properties (as the result of scission) to nuclear energy transfer (displacement reactions). When an energetic ion impinges on a polymer, its orbital electrons are stripped off and the nucleus becomes almost naked until the ion velocity slows down below the Bohr electron velocity of the medium ${ }^{46}$. Figure 4 shows the range of $1 \mathrm{keV} \mathrm{N}^{+}$ions.

A random distribution of irradiated ions is observed generating a relatively symmetric Gaussian. The mean value of the LDPE target depth was close to $70 \AA$ for fluencies of up to $14 \times 10^{5} \mathrm{ions} / \mathrm{cm}^{2}$. The new surface properties of the implanted material are attributed to 
chain scission and crosslinking, which are related to the simultaneous nuclear energy transfer (displacement reactions) and electronic energy transfer (ionization), respectively.

As observed in Fig. 4, obtained by simulations of the effects of impacts by $1 \mathrm{keV}$ of $\mathrm{N}^{+}$ions, the maximum ion range was less than $200 \AA ̊$ A because of continuous energy loss, that can be estimated by applying the Kinchin-Pease model of recoils ${ }^{47,48}$, and a phenomenological model based on equations from Lindhard-Scharf-Schiott (LSS) and Brandt-Kitagawa for electronic stopping ${ }^{49}$. In this process, among other reactions, hydrogen atoms are freed from the polymer causing crosslinking. Although both electronic and nuclear processes cause crosslinking as well as scissions, it has been found that the most important parameter to achieve a high degree of crosslinking is electronic, while nuclear collisions tends to cause degradation ${ }^{50}$. For a given energy, smaller ions penetrate deeper and cause fewer nuclear displacements than heavier ones. However, their maximum attainable is smaller because they have fewer nucleons and attain a lower charge state when stripped.

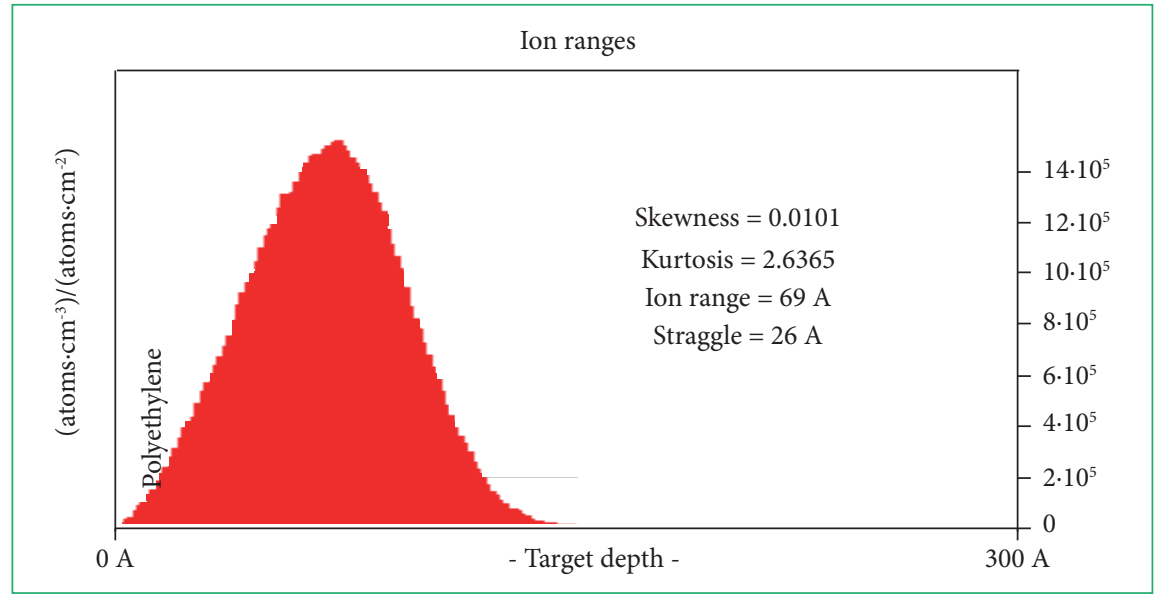

Figure 4: Distribution of $\mathrm{N}+$ ions as a function of target depth.

For engineering applications, the degree of crosslinking and scission as well the depth of the modified layer need to be controlled and can be tailored by optimizing the electronic-to-nuclear ratio by a judicious choice of ion species and ion energy ${ }^{51}$. Experimental results suggest that unsaturation can occur when ion pairs in two neighboring chains overlap ${ }^{52}$, because the SRIM simulation does not take into account the compositional and structural changes of the polymer substrate in the course of the implantation.

\section{Ultraviolet visible near infrared spectroscopy (UV Vis-NIR)}

Figure 5 shows the optical transmittance spectra of LDPE treated with $\mathrm{N}_{2}$ plasmas by PIII coupled at an RF power of $25 \mathrm{~W}$ for $300 \mathrm{~s}$. The applied voltage was $-1040 \mathrm{~V}$ at $300 \mathrm{~Hz}$, while the cycle time was 1, 30, 100 and $500 \mu$ s. Transmittance remains almost constant in the visible range (400 to $700 \mathrm{~nm}$ ), but decreases for $\lambda$ below $400 \mathrm{~nm}$.

Thus, the plasma treatment has influenced quite distinctively the transmittance of LDPE. The optical transmittance decreases for all cycle times because of crosslinking and unsaturation, which depend on the reorganization of molecular groups on the surface, which in

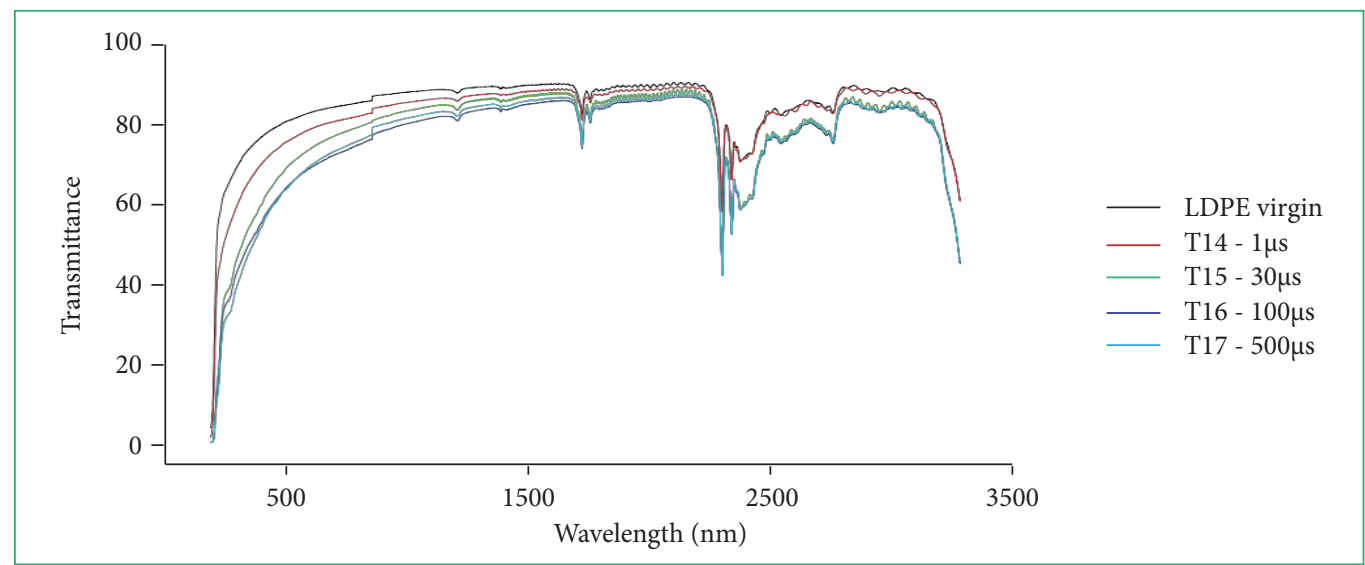

Figure 5: Optical transmittance as function of the wavelength of LDPE samples treated with (13.33 Pa) $100 \mathrm{mTorr}$ of $\mathrm{N}$ for (300 s), $25 \mathrm{~W}$ of RF by different cycle time of Ion Implantation. The parameters of high voltage were $-1040 \mathrm{~V}$ and $300 \mathrm{~Hz}$. 
turn are influenced by distortions along the LDPE chains. Nuclear collisions can be related to plasma kinetics, creating double bonds, promoting interlacing and anchor points along the backbones, and, then, promoting a quite closed polymeric matrix that impedes the free passage of radiation, thus explaining the loss of $\mathrm{T}(\lambda)$ at visible range ${ }^{53}$.

For instance, $1 \mathrm{keV}$ is enough to promote greater fragmentation of species by bond breaking and, subsequently, recombination between different species from the plasma, causing greater distortions in the chains, entanglement and rearrangement; thus, reducing the free path of the incident radiation ${ }^{48}$. The reduction in free path was also reported by Turner ${ }^{54}$.

The stability of polymers under irradiation can be affected by the type of chain-linking group and pendent atoms or groups attached to the backbone of carbon atoms. According to Sant'Ana ${ }^{55}$, free radicals and dangling bonds left in the structure tend to rearrange to minimize their concentration. This reorganization might result in unsaturated carbon bonds $(\mathrm{C}=\mathrm{C})$ or processes of entanglement or crosslinking via covalent bonds when the radicals are created in adjacent chains, thus decreasing the free passage of the incident radiation.

Moreover, the mechanism of electronic stopping can occur involving electromagnetic interaction between the positively charged ion and target electrons. Electronic energy loss can be explained by this mechanism, commonly called "glancing collision" (inelastic scattering, with small momentum transfer $)^{56}$. The literature reports the loss of optical transmittance of visible light $T(\lambda)$ as a consequence of adjacent carbon chains (crosslinks), acting as a barrier for the free path of radiation through the polymeric lattice ${ }^{57}$ which approximates adjacent chains and, then, may fill voids contained in the structure of the polymer chains.

The color change (the polymer tends to become darker, changing from its initial yellow as the fluency increases) has been attributed to the formation of conjugated double bonds, labile products, and other defects during irradiation ${ }^{58,59}$. The color change is generally irreversible but some color centers such as structurally related radicals can be reduced or removed by annealing ${ }^{59}$. This is an important issue for optical applications and future studies. For food packaging, it is important to maintain high transmittance in visible region because one of the criteria for consumer purchasing is visual inspection of the packaged food.

\section{CONCLUSION}

Plasma treatment has been effective to improve the surface properties of LDPE samples. The FTIR indicates the presence of unsaturated bonds and oxygen polar groups owing to the effect of electronic collisions, which create free radicals when nitrogen ions are implanted. The contact angle $(\Theta)$ decreased because of polar group, such as $\mathrm{OH}$ and $\mathrm{CO}$, formed on the surface. Nitrogen ions of $1 \mathrm{keV}$ are assumed to penetrate deeper into the polymer. This condition was considered in this work, equivalent to $-1000 \mathrm{~V}$ of high voltage in the PIII process.

The range of ions projected onto the array, $\left(\mathrm{N}^{+}\right)$which contains larger voids in the microstructure, is notable because the atom has a greater mobility translated by empty spaces, decreasing the energy loss either to nuclear or electronic collisions. The mean penetration depth was $69 \AA$, and the maximum depth was $200 \AA$. Moreover, since the ion energy $(1 \mathrm{keV})$ is much higher than the binding energy of atoms in a polymer, the ion imparts enough energy to the primary replaced atom (recoil) for the following replacements thus producing nonlinear collision cascades. Displaced recoils are capable of creating further recoils and ionization. The authors believe to be predominant more for recoils than ions.

It is concluded that $\mathrm{T}(\lambda)$ is reduced owing due to the crosslinking mechanism that approximates adjacent chains, lowering the passage of the incident radiation. However, the treatment condition (T 14), related to the LDPE implanted with $1 \mu$ s of cycle time, presented the lowest loss transparency (\%) in the visible region, maintaining its high transmittance, which is important for food packaging.

\section{FINANCIAMENTO}

Conselho Nacional de Desenvolvimento Científico e Tecnológico [https://doi.org/10.13039/501100003593]

Fundação de Amparo à Pesquisa do Estado de São Paulo [https://doi.org/10.13039/501100001807]

Project 2017/15853-0

Coordenação de Aperfeiçoamento de Pessoal de Nível Superior [https://doi.org/10.13039/501100002322]

\section{REFERENCES}

1. Juang R-S, Hou W-T, Huang Y-C, Tseng Y-C, Huang C. Surface hydrophilic modifications on polypropylene membranes by remote methane/oxygen mixture plasma discharges. J Taiwan Inst Chem Eng. 2016;65:420-6. https://doi.org/10.1016/j.jtice.2016.04.032

2. Nazarov VG, Stolyarov VP, Gagarin MV. Simulation of chemical modification of polymer surface. J Fluor Chem. 2014;161:120-7. https://doi.org/10.1016/j.jfluchem.2014.01.021 
3. Kharitonov AP, Simbirtseva GV, Tressaud A, Durand E, Labrugère C, Dubois M. Comparison of the surface modifications of polymers induced by direct fluorination and rf-plasma using fluorinated gases. J Fluor Chem. 2014;165:49-60. https://doi.org/10.1016/j. jfluchem.2014.05.002

4. Gancarz I, Bryjak M, Kujawski J, Wolska J, Kujawa J, Kujawski W. Plasma deposited fluorinated films on porous membranes. Mater Chem Phys. 2015;151:233-42. https://doi.org/10.1016/j.matchemphys.2014.11.059

5. Sant'Ana PL, Bortoleto JRR, Cruz NC, Rangel EC, Durrant SF. Study of wettability and optical transparency of pet polymer modified by plasma immersion techniques. Rev Bras ApI Vac. 2017;36(2):68-74. https://doi.org/10.17563/rbav.v36i2.1050

6. Gorjanc M, Savić A, Topalić-Trivunović L, Mozetič M, Zaplotnik R, Vesel A, Gruji区 D. Dyeing of plasma treated cotton and bamboo rayon with Fallopia japonica extract. Cellulose. 2016;23(3):2221-8. https://doi.org/10.1007/s10570-016-0951-9

7. Vukušić T, Vesel A, Holc M, Ščetar M, Jambrak AR, Mozetič M. Modification of physico-chemical properties of acryl-coated polypropylene foils for food packaging by reactive particles from oxygen plasma. Materials. 2018;11(3):372. https://doi.org/10.3390/ ma11030372

8. López-García J, Primc G, Junkar I, Lehocký M, Mozetič M. On the hydrophilicity and water resistance effect of styrene-acrylonitrile copolymer treated by CF4 and O2 plasmas. Plasma Process Polym. 2015;12(10):1075-84. https://doi.org/10.1002/ppap.201400216

9. Pankaj SK, Bueno-Ferrer C, Misra NN, Milosavljević V, O'Donnell CP, Bourke P, et al. Applications of cold plasma technology in food packaging. Trends Food Sci Technol. 2014;35(1):5-17. https://doi.org/10.1016/j.tifs.2013.10.009

10. Sant'Ana PL. Plásticos comerciais tratados a plasma para dispositivos ópticos e embalagens alimentícias [Tese]. [Sorocaba]: Universidade Estadual Paulista Julio de Mesquita Filho; 2014.

11. Sant'Ana PL, Bortoleto JRR, Cruz NC, Rangel EC, Durrant SF, Botti LMC, et al. Surface properties of PET polymer treated by plasma immersion techniques for food packaging. Int J Nano Rech. 2018;1(1):33-41.

12. Sant'Ana PL, Bortoleto JRR, Cruz NC, Rangel EC, Durrant SF, Botti LMC, et al. Surface properties and morphology of PET treated by plasma immersion ion implantation for food packaging. Nanomed Nanotechnol. 2018;3(3):000145. https://doi.org/10.23880/nnoa16000145

13. Rangel EC, Bento WCA, Kayama ME, Schreiner WH, Cruz NC. Enhancement of polymer hydrophobicity by SF6 plasma treatment and argon plasma immersion ion implantation. Surf Interface Anal. 2003;35(2):179-83. https://doi.org/10.1002/sia.1518

14. Islabão Gl. Blendas de polietileno de ultra alto peso molar (PEUAPM) com Polietileno linear de média densidade (PELMD) para rotomoldagem [Dissertação]. [Porto Alegre]: Universidade Federal do Rio Grande do Sul; 2005.

15. Rubin II. Handbook of plastic materials and technology. India: Wiley; 1990.

16. Bolsoni E. Estudo da reprocessabilidade do polietileno de baixa densidade [Dissertação]. [Campinas]: Universidade Estadual de Campinas; 2001

17. Yasuda HK. Plasma polymerization. Michigan: Academic Press; 1985. https://doi.org/10.1016/C2012-0-01688-2

18. D’Agostino R. Plasma deposition, treatment, and etching of polymers. Boston: Academic Press; 1990.

19. Chapman BN. Glow discharge processes: sputtering and plasma etching. New York: Wiley; 1980

20. Fowkes FM. Role of acid-base interfacial bonding in adhesion. J Adhes Sci Technol. 1987:1(1):7-27. https://doi. org/10.1163/156856187X00049

21. Griffith JE, Grigg DA. Dimensional metrology with scanning probe microscopes. J Appl Phys. 1993;74(9):R83. https://doi. org/10.1063/1.354175

22. Kinchin GH, Pease RS. The displacement of atoms in solids by radiation. Rep Prog Phys. 1955;18:1-51. https://doi.org/10.1088/0034$4885 / 18 / 1 / 301$

23. Suzuki $\mathrm{Y}$, Kusakabe M, Akiba $\mathrm{H}$, Kusakabe $\mathrm{K}$, Iwaki M. In vivo evaluation of antithrombogenicity for ion implanted silicone rubber using indium-111-tropolone platelets. Nucl Instrum Methods Phys Res B. 1991;59-60(1):698-704. https://doi.org/10.1016/0168$583 \times(91) 95306-X$

24. Sakudo N, Mizutani D, Ohmura Y, Endo H, Yoneda R, Ikenaga N, et al. Surface modification of PET film by plasma-based ion implantation. Nucl Instrum Methods Phys Res B. 2003;206:687-90. https://doi.org/10.1016/S0168-583X(03)00824-3

25. Kobayashi $\mathrm{H}$, Shen M, Bell AT. Effects of reaction conditions on the plasma polymerization of ethylene. J Macromol Sci A. 1974;8(2):373-91. https://doi.org/10.1080/00222337408065836

26. Tibbitt JM, Bell AT, Shen M. Effects of reaction conditions on the structure of plasma-polymerized ethylene. J Macromol Sci A. 1977;11(1):139-48. https://doi.org/10.1080/00222337708061258

27. Rangel RCC. Aplicação do eletrocapilaridade na manipulação de microgotas [Dissertação]. [Bauru]: Universidade Estadual Paulista; 2008

28. Dong H, Bell T. State-of-the-art overview: ion beam surface modification of polymers towards improving tribological properties. Surf Coat Tech. 1999;111(1):29-40. https://doi.org/10.1016/S0257-8972(98)00698-7 
29. Pandiyaraj KN, Selvarajan V, Heeg J, Junge F, Lampka A, Barfels T, et al. Influence of bias voltage on diamond like carbon (DLC) film deposited on polyethylene terephthalate (PET) film surfaces using PECVD and its blood compatibility. Diam Relat Mater. 2010;19(79):1085-92. https://doi.org/10.1016/j.diamond.2010.03.016

30. Sakudo N, Mizutani D, Ohmura Y, Endo H, Yoneda R, Ikenaga N, et al. Surface modification of PET film by plasma-based ion implantation. Nucl Instrum Methods Phys Res B. 2003;206:687-90. https://doi.org/10.1016/S0168-583X(03)00824-3

31. Kim Y, Lee Y, Han S, Kim K-J. Improvement of hydrophobic properties of polymer surfaces by plasma source ion implantation. Surf Coat Technol. 2006;200(16-17):4763-9. https://doi.org/10.1016/j.surfcoat.2005.04.035

32. Chassé M, Ross GG. Modification of wetting properties of SiOx surfaces by Ar implantation. Nucl Instrum Methods Phys Res B 2002;193(1-4):835-45. https://doi.org/10.1016/S0168-583X(02)00913-8

33. Rupp F, Scheideler L, Rehbein D, Axmann D, Geis-Gerstorfer J. Roughness induced dynamic changes of wettability of acid etched titanium implant modifications. Biomaterials. 2004;25(7-8):1429-38. https://doi.org/10.1016/j.biomaterials.2003.08.015

34. Feitor MC. Estudo da molhabilidade de tecidos 100\% poliéster tratados em plasma N2/O2 e O2 em função do seu envelhecimento natural [Dissertação]. [Natal]: Universidade Federal do Rio Grande do Norte; 2006.

35. Darbello SM. Estudo da reciclagem mecânica de poli (cloreto de vinila) - PVC - proveniente de resíduos da construção civil [Dissertação]. [Bauru]: Universidade Estadual Paulista; 2008.

36. Rao GR, Wang ZL, Lee EH. Microstructural effects on surface mechanical properties of ion-implanted polymers. J Mater Res. 1993;8(4):927-33. https://doi.org/10.1557/JMR.1993.0927

37. Gengenbach TR, Griesser HJ. Post-deposition ageing reactions differ markedly between plasma polymers deposited from siloxane and silazane monomers. Polymer. 1999;40(18):5079-94. https://doi.org/10.1016/S0032-3861(98)00727-7

38. Yasuda H, Sharma AK, Yasuda T. Effect of orientation and mobility of polymer molecules at surfaces on contact angle and its hysteresis. J Polym Sci Pol Phys. 1981;19(9):1285-91. https://doi.org/10.1002/pol.1981.180190901

39. Hudis M, Prescott LE. Surface crosslinking of polyethylene produced by the ultraviolet radiation from a hydrogen glow discharge. $J$ Polym Sci B Polym Lett. 1972;10(3):179-83. https://doi.org/10.1002/pol.1972.110100305

40. Hudis M. Surface crosslinking of polyethylene using a hydrogen glow discharge. J Appl Polym Sci. 1972;16(9):2397-414. https://doi. org/10.1002/app.1972.070160918

41. Hudis M. Plasma treatment of solid materials. In: Techniques and applications of plasma chemistry. New York: John Wiley and Sons; 1974.

42. Yasuda H, Marsh HC, Brandt ES, Reilley CN. ESCA study of polymer surfaces treated by plasma. J Polym Sci A Polym Chem. 1977;15(4):991-1019. https://doi.org/10.1002/pol.1977.170150420

43. Foerch R, Kill G, Walzak MJ. Plasma surface modification of polyethylene: short-term vs. long-term plasma treatment. J Adhes Sci Technol. 1993;7(10):1077-89. https://doi.org/10.1163/156856193X00592

44. Sant'Ana PL. Polymers treated by plasma for optical devices and food packaging: Giving a technological ends for commercial and recycled plastics. Latvia: Scholar's Press.; 2018.

45. Sadeek SA. Synthesis, thermogravimetric analysis, infrared, electronic and mass spectra of Mn(II), Co(II) and Fe(III) norfloxacin complexes. WJ Mol Struct. 2005;753(1-3):1-12. https://doi.org/10.1016/j.molstruc.2005.06.011

46. Casper JM. Physical chemistry of surfaces (3rd Ed.), Arthur W. Adamson, Wiley-Interscience, New York, 1976, 698 pp. \$24.95. J Polym Sci B Polym Lett. 1977;15(10):632-3. https://doi.org/10.1002/pol.1977.13015101447

47. Lee EH, Rao GR, Mansur LK. Super-hard-surfaced polymers by high-energy ion-beam irradiation. Trends Polymer Sci. 1996;4(7):229-37.

48. Sigmund P. On the number of atoms displaced by implanted ions or energetic recoil atoms. Appl Phys Lett. 1969;14(3):114-7. https:// doi.org/10.1063/1.1652730

49. Norgett MJ, Robinson MT, Torrens IM. A proposed method of calculating displacement dose rates. Nucl Eng Des. 1975;33(1):50-4 https://doi.org/10.1016/0029-5493(75)90035-7

50. Ziegler JF, Biersack JP. The Stopping and Range of Ions in Matter. In: Bromley DA (Eds.). Treatise on heavy-ion science. Springer: Boston; 1985. https://doi.org/10.1007/978-1-4615-8103-1_3

51. Lee EH, Rao GR, Lewis MB, Mansur LK. Effects of electronic and recoil processes in polymers during ion implantation. J Mater Res. 1994;9(4):1043-50. https://doi.org/10.1557/JMR.1994.1043

52. Ghosh MK, Mittal KL. Polyimides: fundamentals and applications. In: Plastics engineering. New York: Marcel Dekker; 1996.

53. Wertheimer MR. Plasma polymerization: by H. Yasuda; published by Academic Press, New York, 1985 ; 432 pp. Thin Solid Films 1986;144(1):L107-8. https://doi.org/10.1016/0040-6090(86)90080-5

54. Turner JE. Interaction of ionizing radiation with matter. Health Phys. 2005;88(6):520-44. https://doi.org/10.1097/00004032-20050600000002 
55. Sant'Ana PL. Polímeros tratados a plasma para dispositivos e embalagens: Fornecendo um fim tecnológico aos polímeros comerciais mediante o uso de técnicas de modificação superficial por plasma. Latvia: Novas Edições Acadêmicas, 2019.

56. Lee EH. Ion-beam modification of polymeric materials - fundamental principles and applications. Nucl Instrum Meth B. 1999;151(14):29-41. https://doi.org/10.1016/S0168-583X(99)00129-9

57. Nassau K. The physics and chemistry of color: the fifteen causes of color. Phys Today. 1984;37(12):70-1. https://doi. org/10.1063/1.2916002

58. Factor A, Carnahan JC, Dorn SB, Van Dort PC. The chemistry of $\gamma$-irradiated bisphenol-A polycarbonate. Polym Degrad Stabil. 1994;45(1):127-37. https://doi.org/10.1016/0141-3910(94)90188-0

59. Wallace JS, Sinclair MB, Gillen KT, Clough RL. Color center annealing in $\gamma$ - irradiated polystyrene, under vacuum and air atmospheres. Radiat Phys Chem. 1993;41(1-2):85-100. https://doi.org/10.1016/0969-806X(93)90045-V 